\title{
Correction to: Constructing Landscape History Using the Timeline Method: Case Study of the Landscape in Chengdu Plain, China
}

\author{
Hao Zheng
}

Correction to:

Chapter "Constructing Landscape History Using the Timeline Method: Case Study of the Landscape in Chengdu Plain, China" in: L. Cheng et al. (eds.), New Approach to Cultural Heritage, https://doi.org/10.1007/978-981-16-5225-7_19

The original version of this chapter, the following belated correction has been incorporated: In Chapter "Constructing Landscape History Using the Timeline Method: Case Study of the Landscape in Chengdu Plain, China", the chapter author name "Zheng Hao" has been changed to "Hao Zheng". The erratum chapter has been updated with the changes. 